\title{
Erratum to: A concise review of geographic variation in adult body size in anadromous masu salmon, Oncorhynchus masou
}

\author{
Tsuyoshi Tamate
}

Published online: 20 January 2010

(C) Springer Science+Business Media B.V. 2010

\section{Erratum to: Environ Biol Fish \\ DOI 10.1007/s10641-009-9552-x}

The author wishes to correct his errors in the tables in this article.

All the values for geographic coordinates should be expressed as degrees, minutes, and seconds of latitude ( ${ }^{\circ} ;$ '; ").

The online version of the original article can be found at http:// dx.doi.org/10.1007/s10641-009-9552-x.

T. Tamate $(\bowtie)$

Field Science Center for Northern Biosphere,

Hokkaido University,

Sapporo 060-0809, Japan

e-mail: tamate@exfor.agr.hhokudai.ac.jp 